\title{
The Effect on Nursing Leadership Roles with Succession Planning for the Next Generation of Millennial Nurses
}

\author{
Laura F Sittler* \\ VP of Operations and Chief Nursing Officer, Baylor Surgical Hospital at Fort Worth, USPI/ Tenet Healthcare, USA
}

\begin{abstract}
Healthcare today is a complex and complicated arena. Furthermore, there is the criticality of the vast numbers of registered nurse vacancies that exist due to the long-standing nursing shortage. These factors result in an untenable business model Griffith [1]. The Chief Nursing Officer (CNO) has the burden in the hospital setting of both recruiting and retaining talent for the bedside roles, but as well for the development of the nurse leaders who play an integral role in operationalizing the work of patient care. The role of the nursing leader remains one of the most complex roles in the hospital. There are competing priorities to meet and exceed in every indicator from both patient and clinical expectations of performance. These are in areas such as to high patient experience scores, to value based clinical outcomes payment requirements, to reduction in vacancy in the nurse staff roles, and other key indicators that add stress and strain to the role.
\end{abstract}

\section{INTRODUCTION}

Another key performance indicator is the retention of the workforce, and how to engage the millennial nurse as a loyal employee of the nursing department O'Hara [2]. Without solid succession planning strategies, these millennial nurses are sure to leave the workforce, as well, the role of nursing leadership is likely not something of interest to them as a new generation of learners Bernard [3]; Sittler [4]; Saifman [5].

The present phenomenon is that the Generation Y, known as the millennial generation, are now more than $50 \%$ of the workforce Chung [6]. The baby-boomer generation is no longer the predominant worker and is the fastest to be retiring and aging out of the workforce [3]. Nursing has historically built programs and services around the work philosophy of the baby boomer crowd. These former methods are passé' and need to be phased out as the new generation of millennials are now in the workforce as the next generation to take over at the helm of leadership in the organization [2].

The review of the literature shows that the millennial generation, however, is not likely to choose roles in nursing leadership. There are many other career paths in nursing that the millennial nurse may elect Parrott et al. [7]. Great career choices exist now that are centered on technology, artificial intelligence, advanced practice nursing, and other highly specialized roles as nursing and healthcare change. As millennials choose other roles, the essential role of nursing leadership becomes vacant. Patient care and crucial functions of nursing leadership goes unfilled; creating tenuous quality and safety states for optimal patient care Thompson [8].
Quick Response Code:

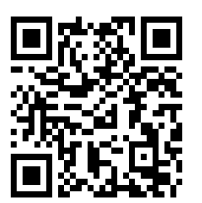

Address for correspondence: Laura F Sittler, VP of Operations and Chief Nursing Officer, Baylor Surgical Hospital at Fort Worth, USPI/ Tenet Healthcare, USA

Received: November 22, 2019 Published: December 10, 2019

How to cite this article: Laura F Sittler. The Effect on Nursing Leadership Roles with Succession Planning for the Next Generation of Millennial Nurses. 2019 - 1(3) OAJBS. ID.000127. DOI: $10.38125 /$ OAJBS.000127 
Themes that have come together from the review of the literature center on the way that nurse leaders must begin to include millennials in the workforce with a different approach to fostering their careers, as well the other key initiative is to provide solid supportive succession planning into leader roles. This paper will explore the role of the nurse leader, and the criticality of the role for optimal healthcare outcomes for patients and consumers. Secondly, this paper will discuss the role of the millennial nurse and the desires of the millennial in the future state of healthcare and hospitals. And finally, this paper will provide detailed discussion on the need for succession planning and filling roles of nursing leadership with millennial nurses for the optimization of our healthcare systems. The aim of this paper is to explore the gaps in succession planning and the chaos created due to the vacancies in nursing leadership. Of interest is to explore what type of succession planning is most valuable to the millennial nurse so that nursing leadership is seen as a viable career choice.

\section{NURSING LEADERSHIP}

Nursing leadership remains one of the most complex roles in the healthcare arena. The nurse leader is someone that can manage and operationalize the business of healthcare. As well the nurse leader is responsible for balancing the work of employee and patient engagement, providing optimal patient outcomes data and results, recruiting and retaining top talent, and managing both cost and salary productivity. Nurse leader skill sets have been changing as healthcare becomes more and more complex Huston [9]. Often there are vacancies in nursing leader roles due to the stress and complexity of the roles.

With the pending crisis in the shortage of nurses at the bedside, nursing leaders have a tall order to fill vacancies and manage the other competing priorities that they find on their daily work plate [8]. Thompson states that "leaders are those that transform the care environment" and in order to meet the demands of the dwindling workforce, these are the same leaders that should be looking at the roles of leadership to provide for succession planning [8]. Thompson further states that as of 2015 there is to be nearly 200,00 to 600,000 nurses that are approaching retirement age, and as the baby boomers leave the workforce, the role of nurse leader becomes more critical in working to solve staffing crisis's [8]. Comparably, is that Bernard [3] reports in her article the fact that of the retirements looming, nearly $80 \%$ of Chief Nursing Officers (CNO) were headed to retirement. The CNO plays the most critical role in nurse leadership, and therefore, leadership roles too are at a crisis point in the vacancy rates predicted by 2013 literature data.

Some researchers have acknowledged that to attract nurse leaders there must be adequate support and succession planning for the nurse leader. For example, Huston [9] observes that in order to build the nurse leader role in the organization, mentoring and authentic leadership are two methods that are critical as part of the leader role. There has historically been weak leadership in nursing the way a nurse was promoted to leader was by demonstrating great clinical skills. This was the "sink or swim" method of promoting leader roles.

Imperative for the role of the nurse leader in the future is to have solid mentoring and to learn the approaches of authentic leadership. In other words, the way to lead with heart and transparency. Authentic leadership is the "glue needed to hold the nursing environment together" states Huston in her paper, that leaders must prepare for the chaos and turmoil associated with a complex healthcare environment and provide true authentic leader skills to those that they lead [10]. Authentic leaders are those that build and sustain healthy work environments, their leadership skills are refined, deliberate and organized. The continuity of leadership in the organization is crucial for the overall performance of the business unit and leads to improved patient outcomes and retainment of nursing staff McCallin [11]; Bondas [12].

\section{MILLENNIAL NURSES}

Millennial nurses now compromise more than $50 \%$ of the workforce in the hospital setting. The desires of the millennial and the things millennials want in their work must be a dominant management tactic of current leaders in order to recruit and retain these young nurses. Saifman [5] took the lead on presenting more interchange on the desires of the millennial nurse in their recent qualitative interpretative phenomenological study, where they looked at the responses of 35 millennial nurses and their perceptions of succession planning and retention actions that meet their desires for optimal career growth. What they found was millennials crave mentoring and growth opportunities with a supportive environment in which to learn and prosper as a new nurse.

Likewise, in another study conducted by $0^{\prime}$ Hara [2] where in a descriptive study they were able to define via the Professional Practice Work Environment Inventory (PPWEI) survey, that supportive mentoring and authentic leadership is the key to retaining the millennial workforce. Millennials desire different supportive mechanisms from their leaders than other generations before them, some of the most notable differences in the work groups are that millennials desire work that is flexible, providing more time to their personal life than work life. They as well are now one of the most educated generations, and with that they desire coaches and mentors for bosses. They desire to be recognized for their hard work and rewarded with praise and acknowledgement. Overall, they desire meaningful, purposeful work, and look for jobs that allow them to grow and learn at rapid paces.

When supportive work environments do not exist for the millennial nurse, data shows that nearly $57 \%$ of the nurses will leave a job after two (2) years of employment due to disengagement in the workplace. This disengagement is directly related to the work qualities that exist in the environment. Moreover, without a supportive boss, these young nurses will leave [2]. Therefore, the way to retain this work group is to work on improving their leaders, and focus on a mentoring, engaged, supportive boss that these younger nurses desire in their work environments. The literature shows that the more time the nurse leader spends with the millennial nurse and builds positive meaningful relationships, these staff nurses are further apt to trust in their leaders and be an engaged work team.

In Parret et al. [7] their research shows the more the nurses experience things that go wrong in their work shifts, the more they experience burn out and stress that leads to turn over. The interesting phenomenon is that the millennial nurses with high levels of stress and burnout are just as likely to leave the workplace and to leave the career in total. Key to curbing these facts, is that leaders need to be more supportive and visible with this generation of nurse. Frequent reassurances from their leader is necessary for this generation, unlike the generations previously, these new nurses require regular feedback and face time with their leaders. In Sherman et al. [13] the authors discuss that the newer generations 
are tech savvy and independent, they desire feedback and instant information; therefore, nurse leaders must learn what skills are needed to engage their millennial nurse workforce.

The younger generations too are the most adept at avoiding leader roles, as the roles are complex and highly stressful. There are very few studies that look at the interest of the generation $\mathrm{Y}$ nurse in assuming nurse leader roles. This is a gap in the research, to realize that the next generation of worker is now already $50 \%$ of the workforce and is void of choosing a leader role in the healthcare setting. This is a big concern as baby boomer nurses begin to age out and leadership roles become vacant. There must be more focus by both existing nursing leaders and researchers on the millennial taking on the role of nursing leadership in the healthcare setting.

The current pipeline of millennial nurses taking on these roles is just not adequate and nursing leadership will suffer due to inadequate interest by the millennial generation. According to Titzer [10] they demonstrate in their writings that baby boomers are retiring, and predictions show nearly 70,000 additional vacancies in nursing leadership roles by the year 2020, which is right around the corner in terms of time [6]. Therefore, the crisis of vacant nursing leadership roles is already present, and millennials are the answer to ensuring these critical roles are filled with qualified nurses. These roles must be filled by "competent, qualified and well-prepared people" that are ready for the future of nursing leadership states McCallin [11] in their research Alvarado [14]. Nurse succession planning is the way in which to ensure there are qualified nurse millennials in these roles.

\section{NURSE SUCCESSION PLANNING}

In the literature there is evidence that nurse succession planning is sorely lacking in the development of nurse leader roles; this adds to the crisis that is vacant leadership roles [1]. When succession planning is absent, leadership stability, service continuity and job satisfaction are compromised as is the safe practice of care and optimal clinical outcomes for patients. Previous ways in which to be recognized for a leader roles was to work hard and try to get noticed, this process of trying to show your boss that you are a "rising star" without real commitment is fruitless and leads to disengagement [4]. Instead, succession planning is intentional promotion and planning, one that tackles key skills development and engages that nurse mentee into a "dyad-style" learning role that fosters engagement and enthusiasm for the new role as leader [4].

Nurse leader roles are left vacant due to the lack of candidates for the roles, and a vacant role allows a new staff nurse the ability to move up and take on the leader role. The issues are that the millennial nurses will not take on these roles without the proper succession planning and mentoring Doria [15]. Formal succession planning should be in place in the organization in order that when opportunities arise, there is a concrete methodology of fostering partnerships between new nurses and experienced nurse managers and leaders $[4,12,15]$. Mentorship is the key component to engaging this new generation of millennial nurses into choosing nursing leadership roles St Denis [16].

Most organizations have left succession planning as an afterthought, there is little in the way of preplanning and real development to structure solid succession plan programs Waxman [17]. In fact, there is little research to show that millennials will choose leader roles without succession planning. Succession planning is critical to the ability to fill nurse leader roles. These roles are pivotal to good hospital management and continuity of care for patients. No longer can leaders be appointed to roles without formal training and support, as well the new generations will not accept this process as prior generations Gooch [18]; Batcheller [19].

In Trepanier \& Crenshaw, their paper addresses a key concern, and that is whether the current nurse leaders that are aging out are at point in their careers where they are willing to share wisdom and knowledge with the next generation. If knowledge sharing is not part of the responsibility of the older generations, then the millennials have no role models to lean upon. It is expected that in order to foster continuity with the nursing leader roles, that leaders would succession plan, foster and mentor eagerly, however, succession planning is "anemic in organizations" Trepanier [20]. In fact, in their article they show that only $21 \%$ of hospitals have any type of succession planning process in place for nurse leaders and nothing in place for those that are "rising stars" Phillips [21].

If nurse leader roles are not filled with qualified young millennial leaders, there is a crisis on the horizon in healthcare leadership. It is paramount at this stage to begin to ensure adequate nurses are skilled and trained in the role of nurse leader. Leaders are those that provide the vision, strategy and focus for the organization. Without the millennial as the most predominant group in the workforce involved in leadership, there will be an "absolute crisis" when it comes to the pending unfilled roles of nursing leaders [1].

\section{CONCLUSION}

In summary, the critical shortage of nurses in the workforce is a top priority for nurse leaders to address, but even more important is to understand the new generations of millennials that are coming into the workforce to take on these open roles in nursing. The millennials have desires for engagement and aspirations that allow them to grow their careers expediently. Millennials are apt to choose roles that are tech savvy, includes technology, advanced practice roles and other roles that include information technology Price [22]; Fang [23]; Keys [24]; Scully [25].

The role of nurse leader is one that is seen as stressful, complex and unbearable for the millennial nurse. The role of nurse leader is becoming more and more vacant as baby boomers are aging out; and there is really no one to back fill the open positions. Nursing leadership provides the strength to the nursing services in the organization, one that requires skills, strategy and vision to ensure continuity of expert patient care outcomes. Losing leaders in the hospital setting is approaching a crisis state.

There continues to be a lack of succession planning to ensure roles are filled timely. In fact, most organizations are void of any type of succession planning process. Millennials must be looked upon as the generation to fill these roles, yet there is scant research provided on the desires of millennials and how succession planning would drive their desire for nursing leader roles. It is time now for the current nurse leaders to share knowledge, and work towards creating environments that attract millennials to the field of nursing leadership.

The literature shows that millennials are looking for supportive bosses that subscribe to thoughtful succession planning and mentoring. The research to close the gap in this area of work force development is to discover what succession planning methods are best for millennials. With proper mentoring and training, millennials will be sure to choose a career in nursing leadership. 


\section{REFERENCES}

1. Griffith MB (2012) Effective succession planning in nursing: a review of the literature. J Nurs Manag 20(7): 900-911.

2. O’Hara M, Burke D, Ditomassi M, Lopez RP (2019) Assessment of millennial nurses' job satisfaction and professional practice environment. J Nurs Adm 49(9): 411-417.

3. Bernard N (2014) Who's next? Developing high potential nurse leaders for nurse executive roles. Nurse Leader 12(5): 51-61.

4. Sittler LF, Criswell JR (2019) Using a dyad model for mentoring: The role of the CNO in growing the next generation of executive nurse leaders. Nurse Leader 17(4): 321-324.

5. Saifman H, Sherman RO (2019) The experience pf being a millennial nurse manager. J Nurs Adm 49(7-8): 366-371.

6. Chung SM, Fitzsimmons V (2013) Knowing generation Y: a new generation of nurses in practice. Br J Nurs 22(20): 1173-1179.

7. Parrott L, Cazzell M, Dragon W, Basham G (2019) Understanding key drivers of staff and manager engagement: linking research to leadership. Nurse Leader 17(3): 248-252.

8. Thompson P (2008) Key challenges facing american nurse leaders. J Nurs Manag 16(8): 912-914.

9. Huston C (2008) Preparing nurse leaders for 2020. J Nurs Manag 16(8): 905-911.

10. Titzer JL, Shirey MR (2013) Nurse manager succession planning: a concept analysis. Nurs Forum 48(3): 155-164.

11. McCallin A, Bamford WA, Frankson C (2009) Leadership succession planning: a key issue for the nursing profession. Nurse Leader 7(6): 4044.

12. Bondas T (2006) Paths to nursing leadership. J Nurs Manag 14(5): 332 339.
13. Sherman RO, Saifman H, Shwatz RC, Shwatz C (2015) Factors that lead generation Y nurses to consider or reject nurse leader roles. Nursing Plus Open 1: 5-10.

14. Alvarado L (2013) The golden hour of nursing. Nurse Leader. 11(4): 5053.

15. Doria H (2015) Successful transition from staff nurse to nurse manager Nurse Leader 13(1): 78-81.

16. St Denis V (2016) Meet the millennials: a new generation of nursing leaders. Can Nurse 112(6): 28-30.

17. Waxman KT, Delucas C (2014) Succession planning: Using simulation to develop nurse leaders for the future. Nurse Leader 12(5): 24-28.

18. Gooch P (2017) Creating a mentoring culture for new and seasoned chief nurse executives in a health system. Nurse Leader 15(5): 341-344.

19. Batcheller J, Zimmerman D, Pappas S, Adams J (2017) Nursing's leadership role in addressing the quadruple aim. Nurse Leader. 15(3): 203-206.

20. Trepanier S, Crenshaw J (2013) Succession planning: a call to action for nurse executives. Journal of Nursing Management 21(7): 980-985.

21. Phillips T, Evans J, Tooley S, Shirey MR (2018) Nurse manager succession planning: A cost-benefit analysis. J Nurs Manag 26(2): 238-243.

22. Price S, Hall McGillis L, Angus J, Peter E (2013) The social context of career choice among millennial nurses: implications for interprofessional practice. Journal of Interprofessional Care 27(6): 509-514.

23. Fang D, Kesten K (2017) Retirements and succession of nursing faculty in 2016-2025. Nurs Outlook 65(5): 633-642.

24. Keys Y (2014) Looking ahead to our next generation of nurse leaders: Generation X nurse managers. J Nurs Manag 22(1): 97-105.

25. Scully NJ (2015) Leadership in nursing: the importance of recognizing inherent values and attributes to secure a positive future for the profession. Collegian 22(4): 439-444. 